\title{
Appropriate Protection Measures Against COVID-19 in Delivery Room
}

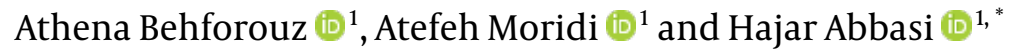 \\ ${ }^{1}$ Preventative Gynecology Research Center, Shahid Beheshti University of Medical Sciences, Tehran, Iran \\ "Corresponding author: Preventative Gynecology Research Center, Shahid Beheshti University of Medical Sciences, Tehran, Iran. Email: haabbasi65@gmail.com
}

Received 2020 May 19; Revised 2021 May 07; Accepted 2021 May 09.

Keywords: COVID-19, Personnel Protective Equipment (PPE), Obstetrician, Labor and Delivery

\section{Dear editor,}

The World Health Organization (WHO) has announced the coronavirus disease 2019 (COVID-19) as a global pandemic, accounting for more than 152 million infected cases up to 1 May 2021 worldwide. Public education provided by experts could minimize the level of communication and social contacts (1). Since the virus is transmitted from human to human, it is important to be alert and take precautionary measures to protect labor room staff, pregnant mothers, and their babies (2). The panic buying and overusing personnel protective equipment (PPE) hast caused the deficiency of N95 masks, surgical masks, and gloves in low-income countries and even high-income ones (3).

Generally, appropriate prevention of virus transmission from/to healthcare workers and patients depends on the effective use of PPE such as gloves, face masks, air purifying respirators, goggles, face shields, respirator, and gowns (4). According to the risk of asymptomatic disease transmission, every unit should make sure that all patients wear a surgical mask and the healthcare staff use a new surgical mask or gloves for each patient $(5,6)$. However, due to the limited capacity of medical resources, executing this recommendation is a challenging issue (7).

Here, we present some brief practical recommendations for delivery rooms:

- Any pregnant woman admitted to the hospital should be triaged for symptoms and risk factors of COVID-19 (Box 1). The patients should be divided into two groups of lowrisk and high-risk patients, according to the screening performed at the triage unit. Indeed the high-risk patients are confirmed or suspected for COVID-19.

- All the patients, regardless of their groups, should be tested for coronavirus PCR, CBC, Diff, ESR, and CRP. For COVID-19 nasopharyngeal swab specimen collection in high-risk group, the staff should use a powered air-

\begin{tabular}{l}
\hline Box 1. Recommended Screening Questionnaire for COVID-19 \\
\hline Questions \\
\hline Have you recently traveled? (in the last 14 days) \\
Have you been exposed to recent travelers or had close contact with them? (in \\
the last 14 days) \\
Have you been exposed to suspected/confirmed COVID-19 patients or had close \\
contacts with them? (in the last 14 days) \\
Do you have fever? \\
Do you have cough? \\
Do you have dyspnea? \\
Do you have headache? \\
Do you have myalgia? \\
Findings \\
$\quad$ Temperature - \\
Respiratory rate - \\
\hline Oxygen saturation - \\
\hline
\end{tabular}

purifying respirator (PARP), and all the personnel should be trained for the correct usage of N95 masks and PARP (2). A PARP is a type of mask that uses a blower to push air through filter container and into the breathing space. In addition, it may have a half or full fitting face piece or helmet.

- The essential rule is to limit the number of staff entering the labor unit, especially the patient room (it is better to make a local policy for any labor unit).

- Once a high-risk pregnant woman with suspected/confirmed COVID-19 is admitted to the isolated delivery room for intrapartum care, the following considerations should be observed: (1) if possible, negative 
pressure isolation rooms should set up for a safe delivery. The ability of converting delivery rooms into negative pressure rooms needs portable high-efficiency particulate air filters; (2) all healthcare staff should wear full PPE such as disposable gowns, N95 masks, latex gloves, and eye protection before entering the isolation room (2); (3) at least, an N95 mask should be used by healthcare providers during the second stage of labor (7); N95 masks should be worn in addition to droplet precaution PPE in the second stage of labor due to certain aerosolizing procedure (8); alcohol based hands rub should be used after contacting each patient (5, 6, 8); after delivery, rooms that are exposed should be cleaned up with routine cleaning and disinfection methods such as hydrogen peroxide vapor and ultraviolet (UV) light, according to the Centers for Disease Control and Prevention (CDC) statement (9).

The present letter aimed to collect useful recommendations from available guidelines to optimize the healthcare personnel protection and limit the interpersonal transmission. We hope the implementation of this guidelines could be lifesaving.

\section{Footnotes}

Authors' Contribution: $\mathrm{AB}$ and HA shared idea and prepared the first draft; all the authors participated in finalizing the manuscript.

Conflict of Interests: No conflict of interest was declared. Funding/Support: There is no funding/support.

\section{References}

1. Karimian M, Borji M, Otaghi M, Mansouri F, Solaimanizadeh L, Salimi E, et al. Special attention to psychiatric centers in COVID-19 pandemic. Arch Clin Infect Dis. 2020;15(2). e103258. doi: 10.5812/archcid.103258.

2. Chua M, Lee J, Sulaiman S, Tan HK. From the frontline of COVID19 - how prepared are we as obstetricians? A commentary. BJOG. 2020;127(7):786-8. doi: 10.1111/1471-0528.16192. [PubMed:32131142].

3. Hopman J, Allegranzi B, Mehtar S. Managing COVID-19 in lowand middle-income countries. JAMA. 2020;323(16):1549-50. doi: 10.1001/jama.2020.4169. [PubMed: 32176764].

4. Livingston E, Desai A, Berkwits M. Sourcing personal protective equipment during the COVID-19 pandemic. JAMA. 2020;323(19):1912-4. doi: 10.1001/jama.2020.5317. [PubMed: 32221579].

5. Wax RS, Christian MD. Practical recommendations for critical care and anesthesiology teams caring for novel coronavirus (2019-nCoV) patients. Can J Anaesth. 2020;67(5):568-76. doi: 10.1007/s12630-02001591-x. [PubMed: 32052373]. [PubMed Central: PMC7091420].

6. MacIntyre CR, Chughtai AA. Facemasks for the prevention of infection in healthcare and community settings. BMJ. 2015;350:h694. doi: 10.1136/bmj.h694. [PubMed: 25858901].

7. Boelig RC, Manuck T, Oliver EA, Di Mascio D, Saccone G, Bellussi F, et al. Labor and delivery guidance for COVID-19. Am J Obstet Gynecol MFM. 2020;2(2):100110. doi: 10.1016/j.ajogmf.2020.100110. [PubMed: 32518901]. [PubMed Central: PMC7270486].

8. Baud D, Giannoni E, Pomar L, Qi X, Nielsen-Saines K, Musso D, et al. COVID-19 in pregnant women - Authors' reply. Lancet Infect Dis. 2020;20(6):654. doi: 10.1016/S1473-3099(20)30192-4. [PubMed: 32197096]. [PubMed Central: PMC7195406].

9. Otter JA, Donskey C, Yezli S, Douthwaite S, Goldenberg SD, Weber DJ. Transmission of SARS and MERS coronaviruses and influenza virus in healthcare settings: The possible role of dry surface contamination. J Hosp Infect. 2016;92(3):235-50. doi: 10.1016/j.jhin.2015.08.027. [PubMed: 26597631]. [PubMed Central: PMC7114921]. 